\title{
Chapter 14 Animal Models of Aspiration Pneumonia
}

\author{
Shinji Teramoto
}

\begin{abstract}
Appropriate animal models of aspiration pneumonia may be required for studying the mechanism of aspiration and aspiration-induced pneumonia. Animal models of AP allow us to investigate distinct types of pneumonia at various disease stages, studies that are not possible in patients. AP animal models should have features of bacterial pneumonia and swallowing abnormality.

Our animal model of aspiration, using recombinant E1-deleted Ad vectors, may be advantageous relative to earlier models for assessing the development of aspiration pneumonia in association with disturbed upper airway reflexes, since DNA virus infection of bronchiolar epithelial cells in the lower respiratory tract can be assessed by the localization and intensity of LacZ gene expression The other candidate model of aspiration was applied for the experimental stroke in mice induced by occlusion of the middle cerebral artery. Aspiration pneumonia was caused by intranasal application of a small amount of Streptococcus pneumoniae.

Acid pneumonitis is a major cause of sterile acute lung injury (ALI), resulting in acute respiratory distress syndrome (ARDS) or Mendelson's syndrome. Several types of animal models of acid aspiration are available using a wide range of developed transgenic models.

Different types of animal models of both aspiration pneumonia and aspiration pneumonitis have considerably aided our understanding of disease pathogenesis and testing and developing of new treatment strategies.
\end{abstract}

Keywords Aspiration pneumonia - Aspiration pneumonitis · Animal models · Mendelson's syndrome · Acid aspiration · Acute lung injury (ALI)

\footnotetext{
S. Teramoto $(\triangle)$

Department of Respiratory Medicine, Tokyo Medical University Hachioji Medical Center,

Tokyo, Japan

e-mail: shinjit-tky@umin.ac.jp
} 


\section{Introduction}

Aspiration pneumonia (AP), which develops after the aspiration of oropharyngeal contents, differs from aspiration pneumonitis, wherein inhalation of gastric contents causes inflammation without the subsequent development of bacterial infection [1, 2]. Because the prognosis of AP as well as aspiration pneumonitis is poor in patients with advancing age, it is difficult to examine the novel therapeutic intervention inducing new drugs for the efficacy on their prognosis in older humans. Animal models of various types of pneumonia are increasingly being utilized in medical research and are responsible for accelerated progress in the treatment of pneumonia and drug development. Because the AP and aspiration pneumonitis are primarily caused by aspiration and swallowing disorder, their animal models should have features of dysphagia animal models in addition to models of respiratory tract injury and infection.

\section{Need for Animal Models of AP and Aspiration Pneumonitis}

Swallowing disorders and aspiration are often found in elderly subjects and patients with chronic pulmonary diseases [3-5]. Matsuse $\mathrm{T}$ and coworkers have demonstrated that recurrent silent aspiration causes a chronic inflammation of bronchioles accompanying a foreign body reaction in older humans [6]. Although many pulmonologists and geriatricians have recognized that silent aspiration and swallowing disorder might be very important for the pathogenesis of aspiration pneumonia and aspiration pneumonitis in older patients [7, 8], the precise mechanism of swallowing abnormality, the relative importance of the effect of age on dysphagia, and the effect of central depressants on aspiration have not been fully elucidated. In addition, suitable animal models for examination of the mechanism of both silent aspiration and massive aspiration such as Mendelson's syndrome have not been well established. Several investigators have shown that aspiration of radiolabeled oropharyngeal secretions into the lungs occurs in humans $[5,9,10]$. These studies suggested that oropharyngeal secretion aspirated to the lower airways during night but did not reveal the pathologic interaction between the aspirate content and airway epithelial infection processes. These studies revealed one aspect or one process in the development of aspiration pneumonia caused by swallowing disorder. Because silent aspiration does not always cause pneumonia, the study of aspiration or dysphagia alone does not provide sufficient information for examining the pathophysiologic mechanism of aspiration pneumonia.

On the other hand, animal models of aspiration pneumonitis have been widely studied. Acid pneumonitis spans the clinical spectrum from asymptomatic to acute respiratory distress syndrome (ARDS), characterized by neutrophilic alveolitis, and injury to both alveolar epithelium and vascular endothelium [11, 12]. Although 
Table 14.1 Candidate biomarkers of gastric aspiration

\begin{tabular}{|c|c|c|c|}
\hline Biomarkers & Summary of clinical data & Merit & Demerit \\
\hline $\begin{array}{l}\text { Pepsin in } B A L \\
\text { fluid }\end{array}$ & $\begin{array}{l}\text { Elevated in ICU population } \\
\text { with subsequent pneumonia } \\
{[14]}\end{array}$ & $\begin{array}{l}\text { Easy to perform under } \\
\text { intubated patients }\end{array}$ & $\begin{array}{l}\text { Not easy to perfume } \\
\text { under general } \\
\text { condition } \\
\text { Half-life of pepsin is } \\
\text { short }\end{array}$ \\
\hline $\begin{array}{l}\text { Lipid-laden } \\
\text { macrophage }\end{array}$ & $\begin{array}{l}\text { Increase with gastric aspiration } \\
\text { in a number of studies [15-17] }\end{array}$ & Semiquantitative & Nonspecific \\
\hline $\begin{array}{l}\text { Soluble- } \\
\text { TREM-1 }\end{array}$ & $\begin{array}{l}\text { Single study reported higher } \\
\text { levels in aspiration vs. } \\
\text { non-aspirated patient groups } \\
{[18]}\end{array}$ & $\begin{array}{l}\text { Standardized } \\
\text { measurement available } \\
\text { for serum }\end{array}$ & $\begin{array}{l}\text { Increased in trauma, } \\
\text { infectious } \\
\text { pneumonia }[19,20]\end{array}$ \\
\hline $\begin{array}{l}C \text {-reactive } \\
\text { protein } \\
(C R P)\end{array}$ & $\begin{array}{l}\text { Elevated in aspiration } \\
\text { pneumonitis and pneumonia } \\
\text { but cannot be used to } \\
\text { distinguish them [21] }\end{array}$ & Easy to measure & Nonspecific \\
\hline $\begin{array}{l}\text { Procalcitonin } \\
(P C T)\end{array}$ & $\begin{array}{l}\text { Tested positive in aspiration } \\
\text { patients vs. non-aspirated } \\
\text { group [22] } \\
\text { N-terminal procalcitonin } \\
\text { elevated in aspiration patients } \\
\text { [23] }\end{array}$ & Widely available & $\begin{array}{l}\text { Much higher levels } \\
\text { were observed in } \\
\text { other infections }\end{array}$ \\
\hline
\end{tabular}

$B A L$ bronchoalveolar lavage fluid, Soluble-TREM-1 soluble-triggering receptor expressed on myeloid cells 1

human studies of ARDS patients have provided us with valuable information about the physiological and inflammatory changes in the lung caused by ARDS, it is difficult to determine the etiology of ARDS, and a wide range of pathophysiology have resulted in a lack of critical information that could be useful in developing therapeutic strategies. Numerous biomarkers have been studied in the context of aspirationinduced lung injury in humans and animals [13]. In Table 14.1, there are potential biomarkers for aspiration that have been studied in humans [12]. However, these markers are not enough to analyze the pathophysiology of aspiration lung disorders. Thus, animal models of aspiration pneumonitis have more advantages to examine the relationships between etiology and biomarkers in the lungs.

\section{Animal Models of Aspiration Pneumonia (AP)}

As we mentioned in the above sentences, appropriate animal models of aspiration pneumonia are useful to explore the mechanism of aspiration and aspiration-induced pneumonia. For the purpose of elucidating the role of disturbed upper airway reflexes in foreign body aspiration into lower airways, we administered an adenovirus (Ad) vector consisting of E1-deleted recombinant adenovirus carrying the Escherichia coli LacZ gene intranasally to mice or guinea pigs with or without 


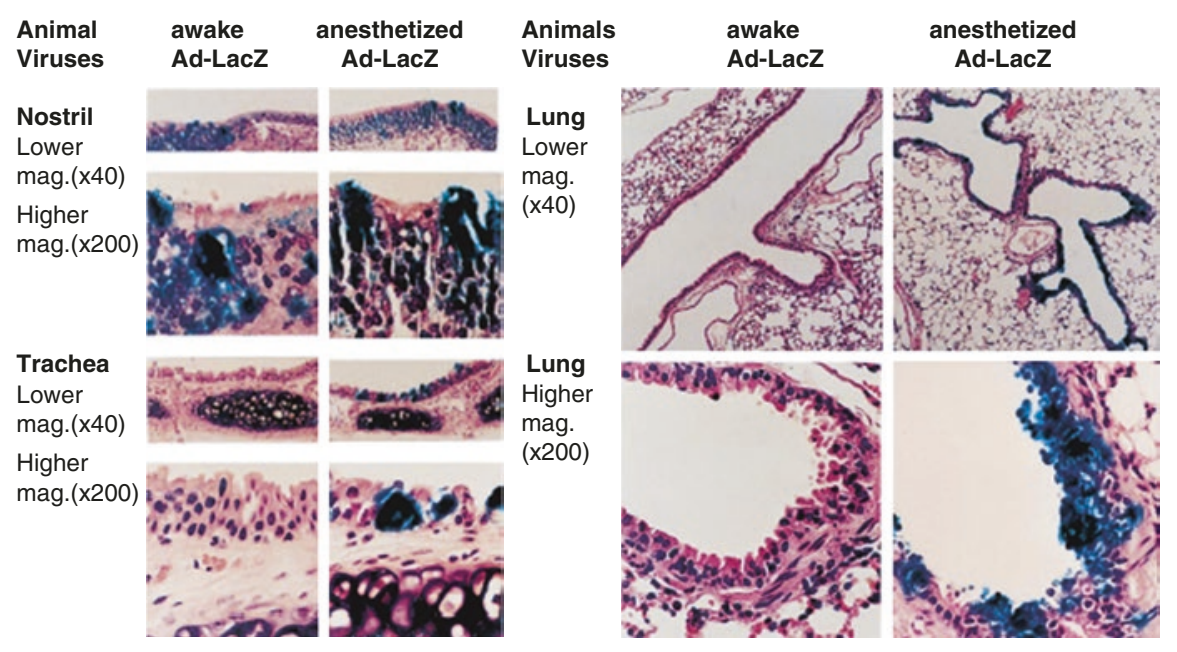

Fig. 14.1 Nostril and tracheal histology findings in 3-mo-old C57BL mice after intranasal administration of E1-deleted adenoviral vector (Ad-CMV-LacZ) with or without pentobarbital anesthesia. Awake mice were given PBS in place of pentobarbital sodium; anesthetized mice given pentobarbital sodium ( $5 \mathrm{mg} / 100 \mathrm{~g}$ body weight) intraperitoneally. Histologic sections were stained with X-gal and H\&E. Original magnification: lower magnification, 340; higher magnification, 3200. Blue-stained cells were considered to express LacZ gene [25].

anesthesia [24, 25]. Because the Ad vector is known to infect airway cells and to express the E. coli LacZ gene in epithelial cells, the distribution in airways of intranasally administered solution containing Ad vectors can be identified by blue staining of LacZ with X-gal staining. In mice given Ad vector, but not phosphate-buffered saline (PBS), intranasally during anesthesia, there was LacZ gene expression in the nostrils, trachea, and lungs, suggesting that with X-gal staining, blue-stained cells indicated transferred LacZ gene expression (Fig. 14.1). These results suggested that aspiration of intranasal solution into lower airways was caused by disturbed upper airway reflexes during anesthesia. This process can be analyzed by the distribution of LacZ gene expression in airways. Further, these phenomena were observed in older animals even under light anesthetic condition, suggesting that aged animals are likely to aspirate oropharyngeal secretions during sedation and/or anesthesia. This novel model of aspiration, generated with the Ad-CMV-LacZ vector, may be useful for elucidating the mechanism of development of aspiration pneumonia in relation to age-related impairment of upper airway reflexes [24, 25].

Prass $\mathrm{K}$ et al. have reported the other candidate model of aspiration, which is applied for the experimental stroke in mice induced by occlusion of the middle cerebral artery (MCAO) [26]. Aspiration pneumonia was caused by intranasal application of a small amount of Streptococcus pneumoniae in phosphate-buffered saline 4 or 14 days after MCAO. Aspiration pneumonia in the stroke animals 

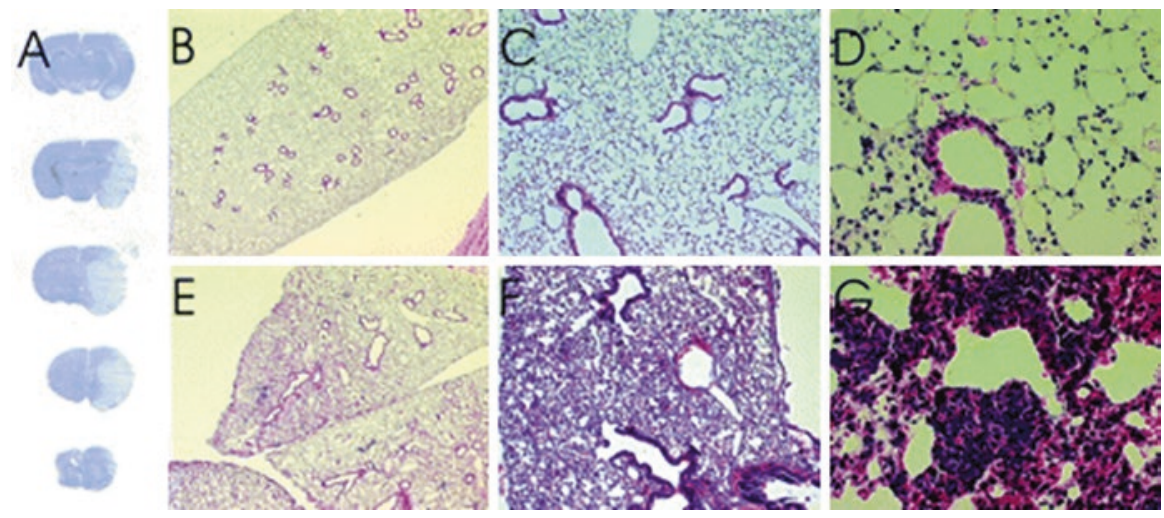

Fig. 14.2 Aspiration pneumonia in stroke but not in sham animals. (a) Histologic examination of the brain. Coronal sections of hematoxylin and eosin-stained mouse brain 72 hours after middle cerebral artery occlusion showing the infarction area. Lung histology of (b-d) sham and (e-g) stroke mice 18 hours after intranasal application of $S$. pneumoniae. Representative $12 \mu \mathrm{m}$ sections of hematoxylin and eosin-stained lungs from $(\mathbf{e}-\mathbf{g})$ middle cerebral artery occlusion but not from (b-d) sham animals revealed signs of severe bacterial pneumonia characterized by (e and $\mathbf{f}$ ) lobar consolidation, edema, necrosis, and neutrophilic infiltrates $(\mathbf{e}$ and $\mathbf{f})$. Magnifications $=(\mathbf{b}$ and $\mathbf{e})$ 25 -fold, (C and F) 100-fold, or (d and $\mathbf{g}$ ) 400-fold. Slides are representative of seven mice per group [26].

outlasted pathophysiologic state of acute stroke but was preventable by betaadrenoreceptor blockade suggesting that immunodepression by sympathetic hyperactivity is essential for progression of bacterial aspiration to pneumonia (Fig. 14.2) [26]. It has been suggested that stroke-associated immunodepression increases the susceptibility to infection. However, it has also been reported that immunodepression following stroke may also have beneficial effects on the prognosis of stroke. Thus, before immunomodulatory therapy can be applied to stroke patients, we need to understand better the interaction of the brain and immune system after focal cerebral ischemia. In the experimental data, cilostazol, which is a phosphodiesterase III inhibitor, increases cAMP-responsive element binding protein (CREB) phosphorylation, leading to upregulation of several apoptotic gene and dopaminergic genes [27]. The CREB phosphorylation and increased expression of dopaminergic genes are involved in the improvement of swallowing function though in the increase of substance. Actually, in an animal model of ischemic stroke, cilostazol induced the increased levels of substance $\mathrm{P}$ and restores swallowing function in the animals [28]. Inversely, blockade of dopamine D1 receptors decreased substance P content in the laryngeal and pharyngeal mucosa, resulting in the impaired swallowing function in animals. Although extrapolation of these experimental results to the clinical situation must be performed with caution, the growing insight into these mechanisms may open new therapeutic avenues in the treatment of patients sustaining a stroke with aspiration pneumonia. 
Fig. 14.3 Albumin leakage into airways following acid aspiration. Albumin concentration of cell-free BAL fluid from C57BL/6 mice at 2 hours and 5 hours post-acid aspiration. Acid aspiration was compared to 5 hours NS aspiration control $(n=9)$ using an unpaired t-test. Error bars indicate SEM. $*=p<0.05$ [32].

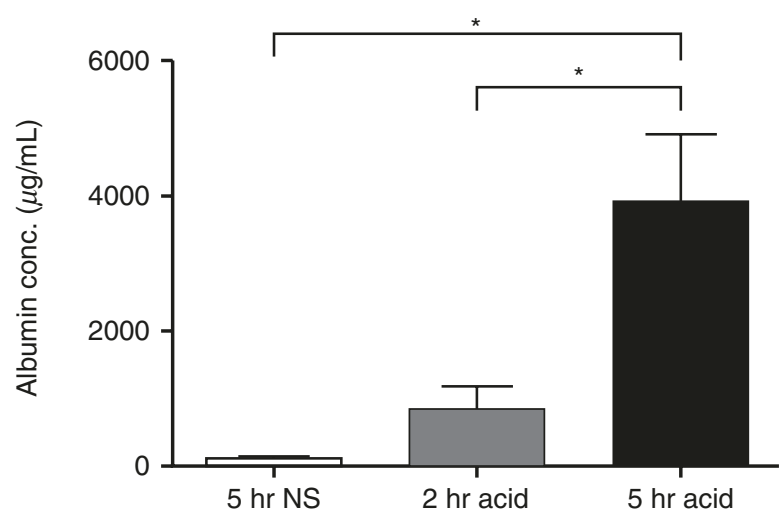

\subsection{Animal Models of Aspiration Pneumonitis}

Acid pneumonitis is a major cause of sterile acute lung injury (ALI), resulting in ARDS, characterized by neutrophilic inflammation and alveolar epithelial injury in humans. This type of aspiration lung injury is categorized as chemical pneumonitis or aspiration pneumonitis [11]. Acid aspiration pneumonitis also induces extrapulmonary organ injury $[29,30]$. The acidic component of the gastric aspiration contributes to both the pneumonitis and predilection to develop a secondary bacterial pneumonia. Aspiration pneumonia is also one of the leading risk factors for ALI and subsequent development of ARDS [12].

Translational animal models are valuable when their pathogenesis and pathophysiology accurately reproduce a concept proven in clinical settings. The murine acid aspiration model recreates a pathogenic scenario that reproduces the low $\mathrm{pH}$ pneumonitis injury in humans.

In our experiences, an animal model by administering hydrochloric acid (HCL) intratracheally to rats every 2 days for 2 weeks does not cause pneumonia [31]. There is no increase of lung free cells, $\mathrm{TNF} \alpha$ production, and elastase-like activity in this animal model. However, Alluri R et al. reported that acid aspiration caused significant leakage of serum proteins into the airways in open tracheostomy gastric acid aspiration murine model. Albumin concentration in the BAL was increased following acid aspiration compared to normal saline (NS) controls at 2 hours and 5 hours (Fig. 14.3) [32]. They also reported that necrotic cells, loss of lung parenchymal architecture, cells and debris within airspaces, and significant polymorphonuclear leukocyte infiltration are observed in the animal model. Chiang SR et al. also found that $0.1 \mathrm{~N}$ acid aspirations alone directly induce lung injury but that the histopathological abnormal alterations of the lungs were not obvious in the mice. On the other hand, $0.1 \mathrm{~N}$ acid aspirations plus the inoculation of bacteria such as Acinetobacter into trachea caused considerable inflammation in the lungs of the same strain of mice [33]. Nagase et al. also reported that acute lung injury induced by acid aspiration of $2 \mathrm{~mL} / \mathrm{kg} \mathrm{HCl}$ ( $\mathrm{pH}=1.5$ ) was slightly observed in control mice but severely observed in a disrupted cytosolic phospholipase A2 (cPLA2) gene [34]. The proteins 
of cPLA2 gene may have a preventable role in acid aspiration-induced lung injury. Tavares A H et al. have recently reported that $2.5 \mathrm{~mL} / \mathrm{kg}$ of intrabronchial $\mathrm{HCl}$ produced substantial yet sublethal acute lung injury in mice but lower doses of $\mathrm{HCl}$ did not result in reproducible and homogenous lung injury [35]. Thus, acid aspiration alone caused transient lung inflammation, but the injury is limited and recovered.

Aspiration of gastric contents induces not only severe pneumonitis but also large airway damages. This condition was determined as Mendelson's syndrome [36]. Mendelson's syndrome is chemical pneumonitis or aspiration pneumonitis caused by aspiration during anesthesia, especially during pregnancy. The condition is severe pneumonitis, but not bacterial pneumonia-like aspiration pneumonia. The lung can be injured directly, such as in pneumonia or with gastric acid aspiration, or indirectly [37]. The condition is closely related to acute respiratory distress syndrome (ARDS) [38]. It is important to develop and characterize an animal model of gastric acid aspiration. Maximal nonlethal lung injury in mice occurs after aspiration of $3.6 \mathrm{~mL} / \mathrm{kg}$ of $\mathrm{pH} 1.25 \mathrm{HCl}$, which simulates gastric acid [39]. Gastric acid aspiration alters alveolar fluid clearance independent of pulmonary blood flow or vascular filtration [40]. Histologic characteristics of the gastric acid aspiration are an acute inflammatory alteration with patchy areas of neutrophilic inflammation, alveolar hemorrhage, and intra-alveolar and interstitial edema. The murine gastric acid aspiration model presented here using HCL employs an open tracheostomy and recreates a pathogenic scenario that reproduces the low $\mathrm{pH}$ pneumonitis injury in humans. Additionally, this model can be used to examine the interaction of a low $\mathrm{pH}$ insult with other pulmonary injurious entities including food particles and bacteria.

Chen $\mathrm{Z}$ et al. demonstrated that vagotomy decreases the neuronal activities of the medulla oblongata and alleviates neurogenic inflammation of airways induced by repeated intraesophageal instillation of $\mathrm{HCl}$ in guinea pigs [41]. This indicates that modulation of neuronal activities is a therapeutic option for neurogenic inflammation of airways following HCL exposure.

\section{Conclusion}

The risk of aspiration pneumonia increases in older adults, which is particularly relevant in the rapidly aging society of developed countries. Animal models of AP and aspiration pneumonitis are useful to examine the mechanism of aspirationassociated lung disorders in vivo. It is not easy to examine the acute therapeutic modality for AP and aspiration pneumonitis in humans. We have developed a novel animal model of aspiration and AP using recombinant E1-deleted Ad vectors under anesthesia. The other candidate model of aspiration was applied for the experimental stroke in mice induced by occlusion of the middle cerebral artery. As an animal model of aspiration pneumonitis, several types of animal models of acid aspiration are available using a wide range of developed transgenic models. We should further examine the mechanism of aspiration-associated lung disorders using a wide variety of animal models of AP and aspiration pneumonitis. 


\section{References}

1. Niederman MS, Fein AM. Pneumonia in the elderly. Clin Geriatr Med. 1986;2:241-68.

2. Marrie TJ, Durant H, Yates L. Community-acquired pneumonia requiring hospitalization: 5-year prospective study. Rev Infect Dis. 1989;11:586-99.

3. Glesson K, Eggli DF, Maxwell SL. Quantitative aspiration during sleep in normal subjects. Chest. 1997;111:1266-72.

4. Feinberg MJ, Knebl J, Tully J, Segall L. Aspiration and the elderly. Dysphagia. 1990;5:1289-93.

5. Kikuchi R, Watabe N, Konno T, Mishina N, Sekizawa K, Sasaki H. High incidence of silent aspiration in elderly patients with community-acquired pneumonia. Am J Respir Crit Care Med. 1994;150:251-3.

6. Matsuse T, Oka T, Kida K, Fukuchi Y. Importance of diffuse aspiration bronchiolitis caused by chronic occult aspiration in the elderly. Chest. 1996;110:1289-93.

7. Nakagawa T, Sekizawa K, Arai H, Sasaki H. High incidence of pneumonia in elderly patients with basal ganglia infarction. Arch Intern Med. 1997;157(321-324):1997.

8. Harkness GA, Bentley DW, Roghmann KJ. Risk factors for nosocomial pneumonia in the elderly. Am J Med. 1990;89:457-63.

9. Huxley EJ, Viroslav J, Gray WR, Pierce AK. Pharyngeal aspiration in normal subjects and patients with depressed consciousness. Am J Med. 1978;64:564-86.

10. Brock-Utne JG, Winning TJ, Rubin J, Kingston HCG. Laryngeal incompetence during neurolept analgesia in combination with diazepam. Br J Anaeth. 1976;48:699-701.

11. Knight PR, Rutter T, Tait AR, Coleman E, Johnson K. Pathogenesis of gastric particulate lung injury: a comparison and interaction with acidic pneumonitis. Anesth Analg. 1993;77(4):754-60.

12. Raghavendran K, Nemzek J, Napolitano LM, Knight PR. Aspiration-induced lung injury. Crit Care Med. 2011;39(4):818-26.

13. Jaoude PA, Knight PR, Ohtake P, et al. Biomarkers in the diagnosis of aspiration syndromes. Expert Rev Mol Diagn. 2010;10(3):309-19.

14. Metheny NA, Clouse RE, Chang YH, et al. Tracheobronchial aspiration of gastric contents in critically ill tube-fed patients: frequency, outcomes, and risk factors. Crit Care Med. 2006;34(4):1007-15.

15. Ahrens P, Noll C, Kitz R, et al. Lipid-laden alveolar macrophages (LLAM): a useful marker of silent aspiration in children. Pediatr Pulmonol. 1999;28(2):83-8.

16. Corwin RW, Irwin RS. The lipid-laden alveolar macrophage as a marker of aspiration in parenchymal lung disease. Am Rev Respir Dis. 1985;132(3):576-81.

17. Parameswaran K, Anvari M, Efthimiadis A, et al. Lipid-laden macrophages in induced sputum are a marker of oropharyngeal reflux and possible gastric aspiration. Eur Respir J. 2000;16(6):1119-22.

18. El Solh AA, Akinnusi ME, Peter M, et al. Triggering receptors expressed on myeloid cells in pulmonary aspiration syndromes. Intensive Care Med. 2008;34(6):1012-9.

19. Mylotte JM, Goodnough S, Naughton BJ. Pneumonia versus aspiration pneumonitis in nursing home residents: diagnosis and management. J Am Geriatr Soc. 2003;51:17-23.

20. Giamarellos-Bourboulis EJ, Mouktaroudi M, Tsaganos T, et al. Evidence for the participation of soluble triggering receptor expressed on myeloid cells- 1 in the systemic inflammatory response syndrome after multiple trauma. J Trauma. 2008;65(6):1385-90.

21. Gibot S, Cravoisy A. Soluble form of the triggering receptor expressed on myeloid cells-1 as a marker of microbial infection. Clin Med Res. 2004;2(3):181-7.

22. Pusch F, Wildling E, Freitag H, et al. Procalcitonin as a diagnostic marker in patients with aspiration after closed head injury. Wien Klin Wochenschr. 2001;113(17-18):676-80.

23. Nylen ES, Snider RH Jr, Thompson KA, et al. Pneumonitis-associated hyperprocalcitoninemia. Am J Med Sci. 1996;312(1):12-8. 
24. Teramoto S, Matsui H, Ohga E, Ishii T, Matsuse T, Ouchi Y. A novel model of aspiration in young and old Guinea-pigs using LacZ gene transduction of adenovirus vector. Br J Anaesth. 1999;83(2):296-301.

25. Teramoto S, Matsuse T, Oka T, Ito H, Fukuchi Y, Ouchi Y. Investigation of effects of anesthesia and age on aspiration in mice through LacZ gene transfer by recombinant E1-deleted adenovirus vectors. Am J Respir Crit Care Med. 1998;158(6):1914-9.

26. Prass K, Braun JS, Dirnagl U, Meisel C, Meisel A. Stroke propagates bacterial aspiration to pneumonia in a model of cerebral ischemia. Stroke. 2006;37:2607-12.

27. Watanabe T, Zhang N, Liu M, Tanaka R, Mizuno Y, Urabe T. Cilostazol protects against brain white matter damage and cognitive impairment in a rat model of chronic cerebral hypoperfusion. Stroke. 2006;37:1539-45.

28. Zhang N, Miyamoto N, Tanaka R, Mochizuki H, Hattori N, Urabe T. Activation of tyrosine hydroxylase prevents pneumonia in a rat chronic cerebral hypoperfusion model. Neuroscience. 2009;158(2):665-72.

29. Weiser MR, Pechet TT, Williams JP, Ma M, Frenette PS, Moore FD, Kobzik L, Hines RO, Wagner DD, Carroll MC, Hechtman HB. Experimental murine acid aspiration injury is mediated by neutrophils and the alternative complement pathway. J Appl Physiol. 1997;83:1090-5.

30. Amigoni M, Bellani G, Scanziani M, Masson S, Bertoli E, Radaelli E, Patroniti N, Di Lelio A, Pesenti A, Latini R. Lung injury and recovery in a murine model of unilateral acid aspiration: functional, biochemical, and morphologic characterization. Anesthesiology. 2008;108:1037-46. https://doi.org/10.1097/ALN.0b013e318173f64f.

31. Sudo E, Fukuchi Y, Ishida K, et al. Diffuse aspiration bronchiolitis (DAB) produced in animals by repeated $\mathrm{HCl}$ microaspiration. Jpn J Geriat. 1994;31:435-40. (in Japanese)

32. Alluri R, Kutscher HL, Mullan BA, Davidson BA, Knight PR. Open tracheostomy gastric acid aspiration murine model of acute lung injury results in maximal acute nonlethal lung injury. $\mathrm{J}$ Vis Exp. 2017;120:54700.

33. Chiang SR, Tang HJ, Chen CH, Chen CC, Lee WY, Chang PC, et al. Acid aspiration provokes the pneumonia caused by multidrug-resistant Acinetobacter baumannii in BALB/c mice. Int $\mathrm{J}$ Infect Dis. 2013;17:e454-60.

34. Nagase T, Uozumi N, Ishii S, Kume K, Izumi T, Ouchi Y, Shimizu T. Acute lung injury by sepsis and acid aspiration: a key role for cytosolic phospholipase A2. Nat Immunol. 2000;1(1):42-6.

35. Tavares AH, Colby JK, Levy BD, Abdulnour RE. A Model of self-limited acute lung Injury by unilateral Intra-bronchial acid Instillation. J Vis Exp. 2019;150:e60024. https://doi. org/10.3791/60024.

36. Mendelson CL. The aspiration of stomach contents into the lungs during obstetric anesthesia. Am J Obstet Gynecol. 1946;52:191205.

37. Baron RM, Levy BD, et al. Acute respiratory distress syndrome. Harrison's principles of internal medicine, 20e. Jameson, JL: McGraw-Hill Education; 2018.

38. Thompson BT, Chambers RC, Liu KD. Acute respiratory distress syndrome. N Engl J Med. 2017;377:562-72.

39. Segal $\mathrm{BH}$, et al. Acid aspiration-induced lung inflammation and injury are exacerbated in NADPH oxidase-deficient mice. Am J Physiol Lung Cell Mol Physiol. 2007;292(3):760-8.

40. Matthay MA, Robriquet L, Fang X. Alveolar epithelium: role in lung fluid balance and acute lung injury. Proc Am Thorac Soc. 2005;2(3):206-13.

41. Chen Z, Chen H, Chen F, Gu D, Sun L, Zhang W, Fan L, Lin Y, Dong R, Lai K. Vagotomy decreases the neuronal activities of medulla oblongata and alleviates neurogenic inflammation of airways induced by repeated intra-esophageal instillation of $\mathrm{HCl}$ in Guinea pigs. Physiol Res. 2017;66(6):1021-8. 